\section{Metastatic renal cell carcinoma in the thyroid gland: ultrasonographic features and the diagnostic role of core needle biopsy}

\author{
Ok Kyu Song' ${ }^{1}$ Ja Seung Koo², Jin Young Kwak, Hee Jung Moon', Jung Hyun Yoon', \\ Eun-Kyung Kim ${ }^{1}$
}

'Department of Radiology and Research Institute of Radiological Science, Severance Hospital, Yonsei University College of Medicine, Seoul; ${ }^{2}$ Department of Pathology, Severance Hospital, Yonsei University College of Medicine, Seoul, Korea

Purpose: The aims of this study were to present the ultrasonographic (US) features of metastatic renal cell carcinoma (RCC) in the thyroid gland and to evaluate the diagnostic utility of fineneedle aspiration (FNA) and core needle biopsy (CNB).

Methods: Eight patients with nine metastatic RCC nodules in the thyroid glands who were treated from January 2002 to March 2015 in a single tertiary hospital were consecutively selected and retrospectively reviewed. US features and clinical history were obtained from the institution's medical database. FNA was performed nine times on eight nodules and CNB was performed six times on six nodules. The diagnostic utility of FNA and CNB was evaluated.

Results: All nine nodules showed mass formation without diffuse thyroid involvement. On ultrasonography, metastatic RCC nodules were solid (100\%), hypoechoic $(100 \%)$, and ovalshaped nodules with a well-defined smooth margin (88.9\%) and increased vascularity $1100 \%$, with $55 \%$ showing extensive vascularity). No calcifications were noted in any nodules. Lymph node metastasis and direct extension to nearby structures beyond the thyroid gland were not found. One FNA (11\%) was able to confirm metastatic RCC, whereas all six CNBs confirmed metastatic RCC.

Conclusion: Metastatic RCC appears as oval-shaped hypoechoic solid nodules with well-defined smooth margins, no calcifications, and increased vascularity on ultrasonography. Characteristic US features along with a previous history of RCC should raise clinical suspicion, and CNB should be performed to make an accurate diagnosis.

Keywords: Thyroid gland; Neoplasm metastasis; Carcinoma, renal cell; Ultrasonography; Biopsy, fine-needle; Biopsy, large-core needle

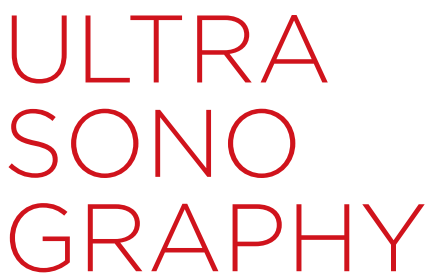

ORIGINAL ARTICLE

https://doi.org/10.14366/usg. 16037 pISSN: 2288-5919 e elSSN: 2288-5943 Ultrasonography 2017;36:252-259

Received: August 26, 2016

Revised: November 3, 2016

Accepted: November 9, 2016

Correspondence to:

Eun-Kyung Kim, MD, PhD, Department of Radiology and Research Institute of Radiological Science, Severance Hospital, Yonsei University College of Medicine, 50-1 Yonsei-ro, Seodaemungu, Seoul 03722, Korea

Tel. $+82-2-2228-7400$

Fax. $+82-2-393-3035$

E-mail: ekkim@yuhs.ac

This is an Open Access article distributed under the terms of the Creative Commons Attribution NonCommercial License (http://creativecommons.org/ licenses/by-nc/3.0/) which permits unrestricted noncommercial use, distribution, and reproduction in any medium, provided the original work is properly cited.

Copyright (c) 2017 Korean Society of Ultrasound in Medicine (KSUM)

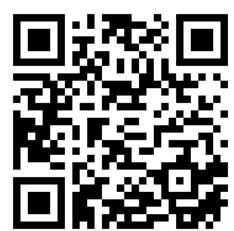

How to cite this article:

Song OK, Koo JS, Kwak JY, Moon HJ, Yoon JH, Kim EK. Metastatic renal cell carcinoma in the thyroid gland: ultrasonographic features and the diagnostic role of core needle biopsy. Ultrasonography. 2017 Jul;36(3):252-259. 


\section{Introduction}

Most malignant thyroid nodules are primary malignancies, and papillary carcinoma is the most common subtype [1]. Thyroid metastasis is relatively uncommon, and usually originates from renal cell carcinoma (RCC), lung cancer, or breast cancer; the incidence of thyroid metastasis has been reported to range from $0.1 \%$ to $6 \%$ of all thyroid malignancies depending on the study design [1-5]. Ultrasonography is commonly performed to detect and differentiate thyroid nodules, and the ultrasonographic (US) features for metastatic thyroid carcinoma include nonspecific findings such as hypoechogenicity, noncircumscribed margins, and increased vascularity $[1-4,6,7]$. RCC is the most common metastatic malignancy found in the thyroid glands, accounting for up to $48.1 \%$ of all metastatic malignancies, and the mean interval between RCC diagnosis and its metastasis to the thyroid gland ranges from 6 to 12.5 years $[2,3,6,8,9]$. Although no management guidelines have been developed for metastatic RCC in the thyroid gland, many reports have asserted that surgical resection of the tumor mass is necessary to improve prognostic outcomes with regard to overall patient survival $[2,7,9-12]$. Therefore, the prompt diagnosis of metastatic RCC is important for treatment planning. However, few reports have addressed the US features specific to metastatic RCC in the thyroid gland. Diagnosing thyroid metastasis is challenging because metastatic nodules mimic benign masses, and in most cases, patients present with no specific symptoms $[2-4,9,13]$. Although fine-needle aspiration (FNA) is commonly used to evaluate thyroid nodules, issues regarding false negative or indeterminate results specific to metastatic RCC have been increasingly recognized $[2,9,14,15]$. However, no report has focused on metastatic RCC. Furthermore, the diagnostic role of core needle biopsy (CNB) specific to metastatic RCC in the thyroid has not been investigated. The purpose of this study was to present the US features of metastatic RCC in the thyroid gland and to evaluate the diagnostic utility of FNA and CNB.

\section{Materials and Methods}

This retrospective review of images and medical records was approved by the Institutional Review Board of our institution, and the requirement for informed patient consent was waived. The medical database of a single tertiary hospital was reviewed for patients with RCC discovered in the thyroid gland from January 2002 to December 2015. A total of eight patients with nine metastatic RCCs in the thyroid gland were included in this study. Metastatic RCC was diagnosed by CNB in two nodules and by pathologic examination of surgical specimens in seven nodules.
The surgical specimen served as the reference standard. However, when a surgical specimen was not available, the CNB result was considered as the final diagnosis and the reference standard. The histopathologic subtype of all metastatic RCCs was clear cell carcinoma.

\section{US Examination}

US examinations were performed by experienced radiologists using an ultrasound system with either a $7.5-\mathrm{MHz}$ or $12-\mathrm{MHz}$ linear array transducer (HDI 5000 or iU, Phillips-Advanced Technology Laboratories, Bothell, WA, USA; Logic 8, GE Medical Systems, Milwaukee, WI, USA). Gray-scale and Doppler ultrasonography were used to evaluate all thyroid nodules. US examinations were performed by one of five board-certified radiologists (4 faculty members, 1 fellow) with 1-20 years of experience in thyroid imaging.

\section{Ultrasound-Guided FNA and CNB Procedure}

FNA was performed nine times on eight of the nine nodules, and CNB was performed six times on six of the nine nodules. USFNA was performed using a 23-gauge needle with a combination of capillary and aspiration techniques according to guidelines suggested by the Korean Society of Thyroid Radiology [16]. USFNA was performed by the same radiologists with US, and USCNB was done by one radiologist with 20 years of experience. Each thyroid nodule was aspirated at least twice, and local anesthesia was not routinely applied. The aspirated materials were expelled on glass slides, which were immediately placed in $95 \%$ alcohol for Papanicolaou staining. Immediate cytologic assessment was not performed. For nodules larger than $5 \mathrm{~cm}$ in size, FNA and CNB were performed concurrently. CNB was also performed when the FNA cytologic evaluation showed inconclusive results (cell paucity or atypia) or when the mass grew in size despite prior benign cytology results. CNB was performed with an 18-gauge semi-automated core biopsy needle (Stericut biopsy needle, co-axial type, TSK Laboratory, Tochigi-Ken, Japan) using the free-hand technique. Local anesthesia with $1 \%$ lidocaine was applied prior to biopsy procedures. The core needle was inserted through the isthmus, via the transisthmic approach, positioning the needle tip at the margin of the nodule. Two core specimens were routinely obtained for each thyroid nodule. After the biopsy, each patient was observed with local compression of the biopsy site for 20 minutes. The diagnostic utility based on histopathological reports from the FNA and CNB was calculated.

\section{Analysis of Images and Medical Records}

All sonograms were retrospectively reviewed by two radiologists (1 and 20 years of experiences in consensus). US features were 
evaluated for characteristics including nodule size, echogenicity, taller-than-wide shape, margin, vascularity, the presence of calcification, and composition. The risk of malignancy based on US features was evaluated using the 2015 American Thyroid Association (ATA) management guidelines for adult patients with thyroid nodules and differentiated thyroid cancer (2015 ATA guidelines) and Korean Thyroid Imaging Reporting and Data System (K-TIRADS) $[17,18]$.

Based on the 2015 ATA guidelines, a solid hypoechoic nodule with at least one suspicious US feature, such as an irregular margin, taller-than-wide shape, microcalcifications or rim calcifications, or extrathyroidal extension, is categorized as a highly suspicious nodule. Intermediate suspicion is assigned to hypoechoic solid nodules without the suspicious US features described above. Isoechoic or hyperechoic solid nodule without suspicious US features are included in the category of low suspicion. Finally, very low suspicion is assigned to spongiform or partially cystic nodules without suspicious US features. K-TIRADS provides a similar risk stratification system, in which a solid hypoechoic nodule with any of three suspicious US features (including microcalcifications, nonparallel orientation or taller-than-wide shape, and a spiculated/ microlobulated margin) falls into category 5 (high suspicion). Solid hypoechoic nodules without any of the three suspicious US features or lesions other than hypoechoic solid nodules with any suspicious US features are considered category 4 (intermediate suspicion). Lesions other than hypoechoic solid nodules without suspicious US features are category 3 (low suspicion) or lower. Vascularity is classified as absent to equivocal (-, similar to surrounding thyroid parenchyma), increased $(+$, intranodal vascularity $<50 \%)$, or extensive $(++$, intranodal vascularity $>50 \%)$ based on the extent of vascularity within the tumor mass. Clinical presentation, age at diagnosis of metastatic RCC in the thyroid gland, and the interval between the initial diagnosis of RCC and thyroid metastasis were obtained from patients' medical records.

\section{Results}

Six men and two women made up the study population, and the mean age at diagnosis of metastatic RCC in the thyroid gland was $59.8 \pm 9.7$ years (range, 49 to 76 years; median, 60.5 years). The

Table 1. Clinical characteristics and diagnostic results of FNA and CNB in patients with metastatic RCC in the thyroid gland

\begin{tabular}{|c|c|c|c|c|c|c|c|c|c|c|c|c|}
\hline \multirow[b]{2}{*}{ No. } & \multirow{2}{*}{$\begin{array}{l}\text { Age } \\
\text { (yr) }\end{array}$} & \multirow[b]{2}{*}{ Sex } & \multirow{2}{*}{$\begin{array}{c}\text { Interval } \\
\text { between RCC } \\
\text { diagnosis } \\
\text { and thyroid } \\
\text { metastasis } \\
\text { (yr) }\end{array}$} & \multirow{2}{*}{$\begin{array}{c}\text { Clinical } \\
\text { presentation }\end{array}$} & \multicolumn{3}{|c|}{ Size } & \multirow{2}{*}{$\begin{array}{c}\text { Nodular } \\
\text { vascularity }\end{array}$} & \multirow{2}{*}{$\begin{array}{c}\text { Interval } \\
\text { between } \\
\text { FNA and } \\
\text { CNB }\end{array}$} & \multicolumn{3}{|c|}{ Pathologic diagnosis } \\
\hline & & & & & $\begin{array}{l}\text { Prior exam } \\
\quad(\mathrm{cm})\end{array}$ & $\begin{array}{c}\text { Interval } \\
\text { (mo) }\end{array}$ & $\begin{array}{c}\text { Most } \\
\text { recent }(\mathrm{cm})\end{array}$ & & & FNA & CNB & $\begin{array}{c}\text { Surgical } \\
\text { specimen }\end{array}$ \\
\hline 1 & 76 & Male & 16 & Palpable mass & - & - & $5.0 \times 2.9 \times 5.5$ & + & 0 & Benign & $\begin{array}{c}\text { Metastatic } \\
\text { RCC }\end{array}$ & - \\
\hline \multirow[t]{2}{*}{2} & 66 & Male & 14 & Palpable mass & $1.5 \times 0.9 \times 1.6$ & 55 & $2.6 \times 1.7 \times 3.5$ & ++ & 3 wk & Nondiagnostic & $\begin{array}{c}\text { Metastatic } \\
\text { RCC }\end{array}$ & $\begin{array}{c}\text { Metastatic } \\
\text { RCC }\end{array}$ \\
\hline & & & & & $0.3 \times 0.3 \times 0.5$ & 55 & $1.4 \times 1.3 \times 2.6$ & + & - & - & - & $\begin{array}{c}\text { Metastatic } \\
\text { RCC }\end{array}$ \\
\hline 3 & 59 & Female & 12 & Palpable mass & - & - & $4.3 \times 2.6 \times 5.1$ & ++ & 0 & $\begin{array}{c}\text { Atypia of } \\
\text { undetermined } \\
\text { significance }\end{array}$ & $\begin{array}{c}\text { Metastatic } \\
\text { RCC }\end{array}$ & $\begin{array}{c}\text { Metastatic } \\
\text { RCC }\end{array}$ \\
\hline 4 & 49 & Male & 6 & Palpable mass & $1.0 \times 0.8 \times 1.2$ & 34 & $1.7 \times 1.4 \times 4.1$ & ++ & 4 wk & $\begin{array}{c}\text { Benign }{ }^{\text {a) }} \text {, } \\
\text { atypia of } \\
\text { undetermined }_{\text {significance }}{ }^{\text {a) }}\end{array}$ & $\begin{array}{c}\text { Metastatic } \\
\text { RCC }\end{array}$ & - \\
\hline 5 & 62 & Male & 4.5 & Asymptomatic & - & - & $1.2 \times 0.8 \times 1.5$ & + & $1 \mathrm{wk}$ & Nondiagnostic & $\begin{array}{c}\text { Metastatic } \\
\text { RCC }\end{array}$ & $\begin{array}{c}\text { Metastatic } \\
\text { RCC }\end{array}$ \\
\hline 6 & 51 & Female & 4.5 & Asymptomatic & $2.0 \times 1.0 \times 2.7$ & 13 & $2.7 \times 1.4 \times 3.2$ & ++ & - & Benign & - & $\begin{array}{c}\text { Metastatic } \\
\text { RCC }\end{array}$ \\
\hline 7 & 49 & Male & 3.5 & Palpable mass & - & - & $4.3 \times 2.0 \times 4.9$ & + & - & $\begin{array}{c}\text { Metastatic } \\
\text { RCC }\end{array}$ & - & $\begin{array}{c}\text { Metastatic } \\
\text { RCC }\end{array}$ \\
\hline 8 & 66 & Male & 16 & Palpable mass & $5.8 \times 2.7 \times 7.2$ & 10 & $5.9 \times 3.3 \times 7.4$ & ++ & $10 \mathrm{mo}$ & Benign & $\begin{array}{c}\text { Metastatic } \\
\text { RCC }\end{array}$ & $\begin{array}{c}\text { Metastatic } \\
\text { RCC }\end{array}$ \\
\hline
\end{tabular}

Age: age at the time of diagnosis of metastatic RCC in the thyroid gland. Size: size of metastatic nodule at the time of diagnosis. FNA, fine-needle aspiration; CNB, core needle biopsy; RCC, renal cell carcinoma.

${ }^{\text {a) }}$ FNA was performed twice with a 34-month interval between each FNA. 
mean interval between the surgical resection of RCC and thyroid metastasis was $9.6 \pm 5.5$ years (range, 3.5 to 16 years; median, 9 years). Six patients presented with a palpable neck mass and two patients were asymptomatic at the time of diagnosis (Table 1). The maximum diameter of the nodules ranged from 1.5 to $7 \mathrm{~cm}$. Eight nodules showed increased fluorodeoxyglucose (FDG) uptake in postoperative FDG-positron emission tomography surveillance, and ultrasonography was performed for the detection, further evaluation, and biopsy of those nodules. Surgical excisions were performed in six patients with seven nodules. Bilateral total thyroidectomy was performed in one patient (nodules in both lobes), whereas thyroid lobectomies were performed in five patients (either right or left depending on the side of the nodule). The remaining two patients

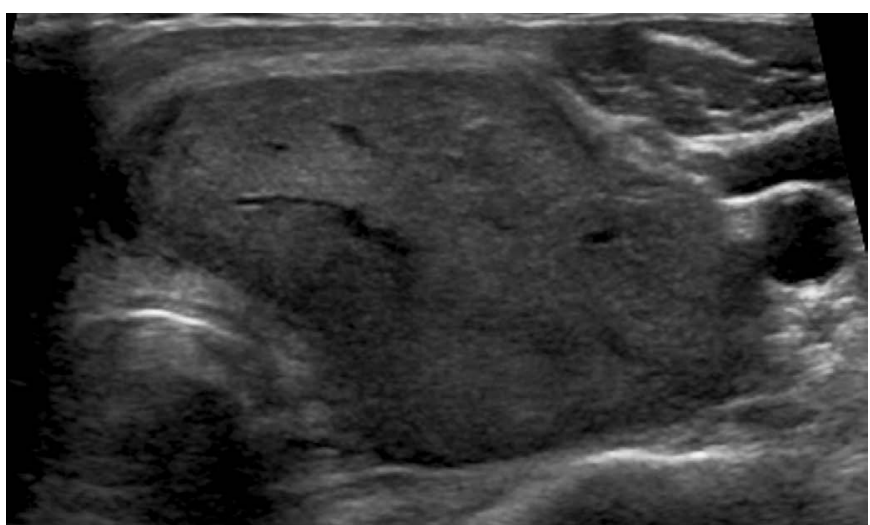

A

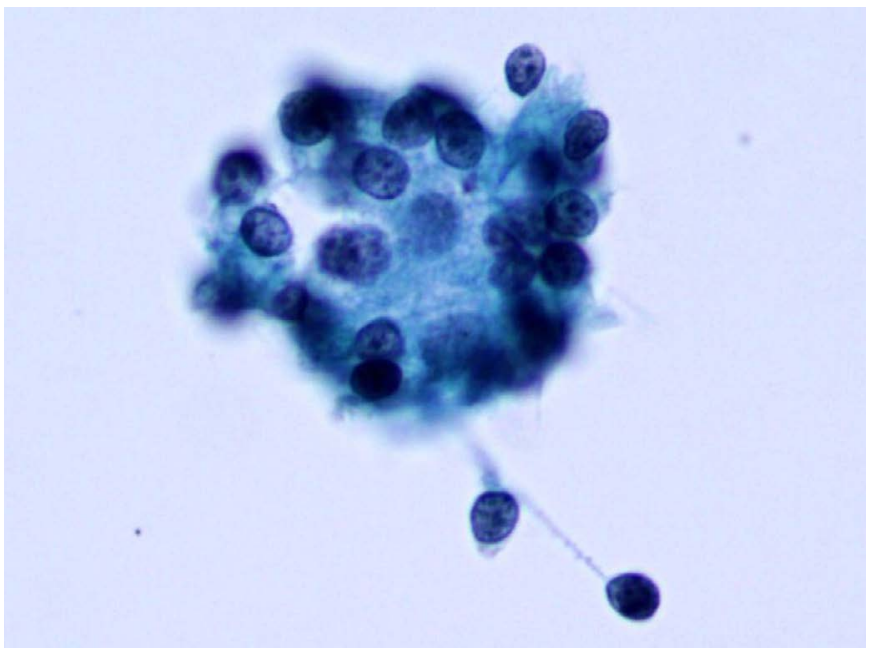

C

Fig. 1. A 59-year-old woman with metastatic thyroid carcinoma (case 3).

$A, B$. The patient presented with a palpable neck mass that showed increased fluorodeoxyglucose uptake in a positron emission tomography scan performed 12 years after renal cell carcinoma was initially diagnosed. Ultrasonography shows (A, transverse; B, color Doppler) a $4.3 \times 2.6 \times 5.1-\mathrm{cm}$ hypoechoic solid mass with a well-defined smooth margin and extensive vascularity. C. Fine-needle aspiration reveals a few round cell clusters showing atypia of undetermined significance/follicular lesion of undetermined significance (Papanicolaou, $\times 400$ ). D. A core needle biopsy shows a solid trabecular tumor with clear cytoplasm $(H \& E, \times 100)$.

e-ultrasonography.org

Ultrasonography 36(3), July 2017 


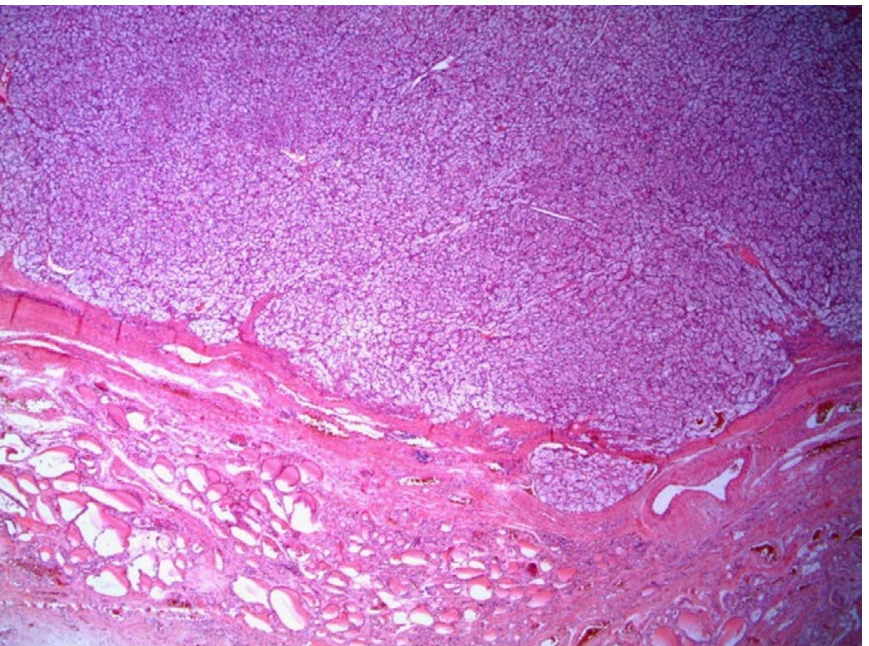

$\mathrm{E}$

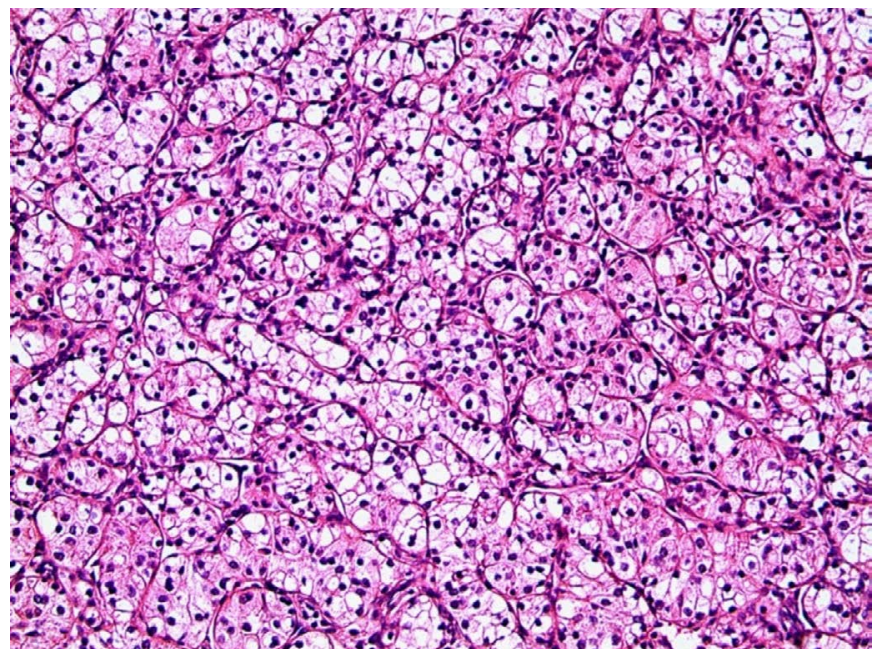

$\mathrm{F}$

Fig. 1. E. After a thyroidectomy, a well-demarcated expanding tumor with a fibrous capsule is shown in low magnification $(H \& E, \times 12)$. F. In higher magnification, the tumor shows clear and eosinophilic cytoplasm $(H \& E, \times 200)$.

moderately suspicious for malignancy and one nodule showed highly suspicious US features due to an irregular margin. According to K-TIRADS, all nodules showed intermediate suspicion for malignancy (K-TIRADS 4).

Four patients had their thyroid nodules evaluated with ultrasonography before diagnosis (Table 1). In these cases, initial ultrasonography revealed well-defined smooth, oval, or roundshaped hypoechoic solid nodules with increased vascularity. Followup evaluations performed 10 to 55 months later showed increased size for all nodules with similar US features (Fig. 2).

\section{Diagnostic Performance of FNA and CNB}

The FNA, CNB, and surgical pathology results are summarized in Table 1. FNA was performed nine times in eight nodules, and only one FNA (11\%) was able to confirm metastatic RCC. In one patient (case 4), FNA was performed twice in a single nodule that showed benign cytological results despite a high clinical suspicion of metastatic malignancy, and subsequent FNA cytology revealed atypia of undetermined significance. This nodule was confirmed as metastatic RCC by CNB. Overall, FNA yielded the following results: nondiagnostic in two lesions (22\%), benign in four lesions (44\%), atypia of undetermined significance in two lesions (22\%), and metastatic RCC in one lesion (11\%). CNB was performed once for each of six nodules. All CNBs confirmed metastatic RCC in the histopathologic analysis, whereas prior FNA of these six nodules had failed to diagnose metastasis. For two nodules, FNA and CNB were performed concurrently and the FNA result was benign or atypia of undetermined significance, whereas CNB confirmed both nodules as metastatic RCC (cases 1 and 3). The CNB specimens showed positive immunohistochemical staining using CD10, alpha-methylacyl-CoA racemase, vimentin, and RCC marker.

\section{Discussion}

Several autopsy series reported in the previous literature have shown that the overall incidence of thyroid metastasis ranges from $1.9 \%$ to $24 \%[1,8]$. Although RCC is the most common malignancy to metastasize to the thyroid glands, its diagnosis is clinically challenging due to its indolent clinical course. Metastatic nodules are found long after surgical resection of the primary mass, with the mean interval ranging from 6 to 12.5 years, and most patients present with no specific symptoms other than a palpable neck mass $[1-3,6,8]$. This is consistent with the characteristic behavior of RCC, in which recurrence occurs after a long latency period [10]. In our study, the mean interval between the initial RCC diagnosis and thyroid metastasis was $9.6 \pm 5.5$ years, and all patients presented with no symptoms other than a palpable neck mass.

The commonly known US features of thyroid metastasis are nonspecific findings including nonhomogeneous hypoechogenicity, noncircumscribed margins, no calcifications, and increased vascularity [1-3]. However, these findings are composed of features from various metastatic tumors from different primary malignancies. Only a few reports have described findings specific to RCC, which include solitary and solid nodules without calcification [14]. According to a recently published study, metastatic RCC in the thyroid gland tends to form a nodular mass that mimics a primary thyroid tumor or even benign masses with few to no suspicious US features [6]. In our study, nine metastatic RCC nodules showed 


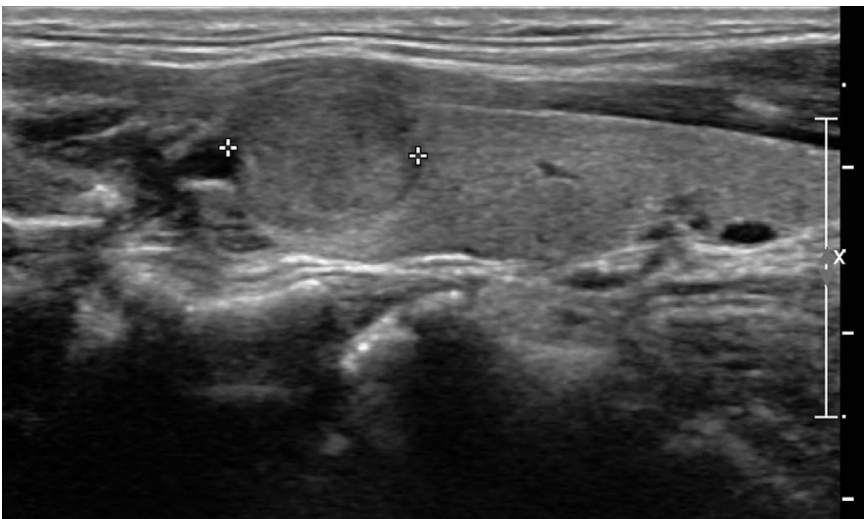

A

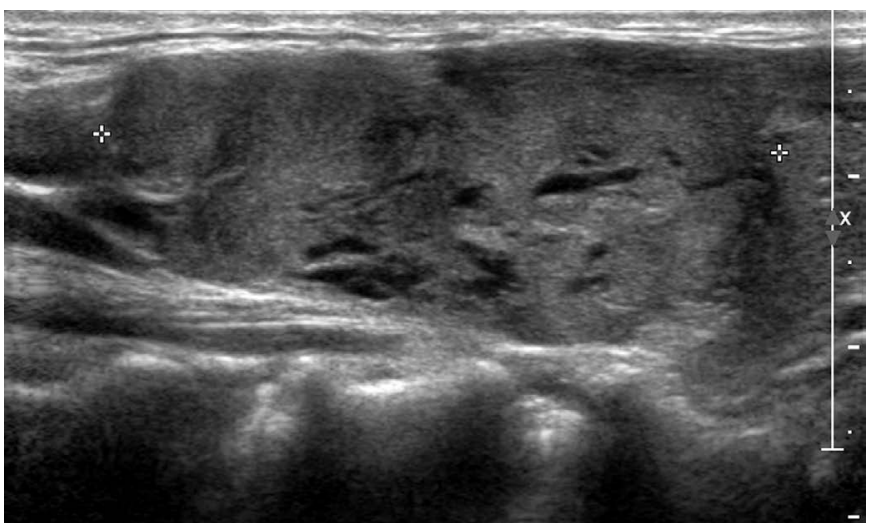

C

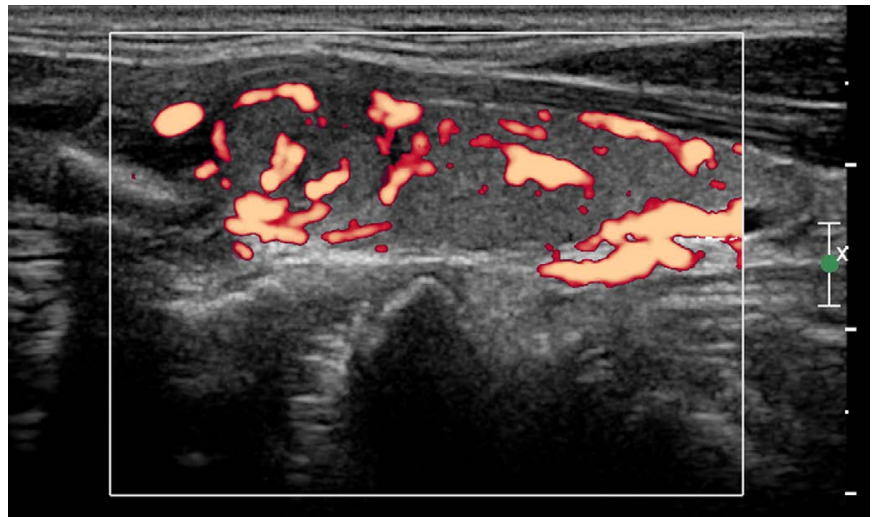

B

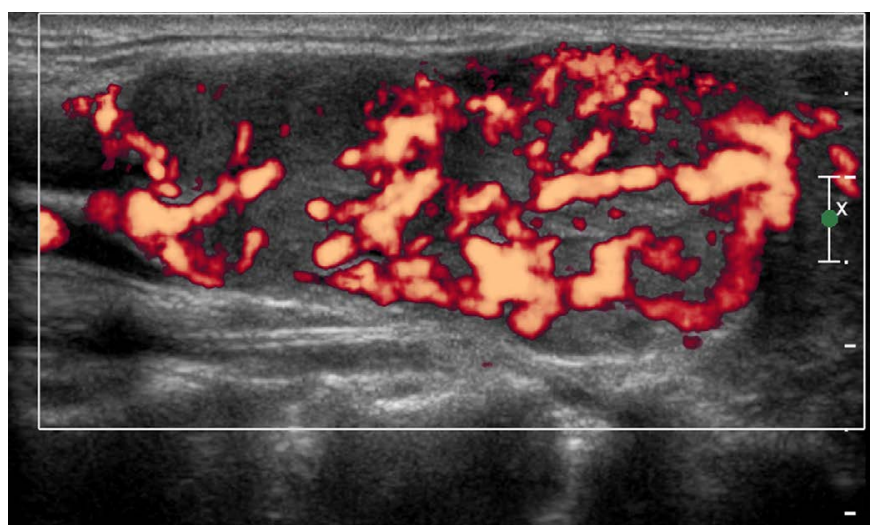

D

Fig. 2. A 49-year-old man with metastatic renal cell carcinoma (case 4).

A, B. Initial ultrasonography (A, longitudinal; B, color Doppler) shows a 1.0×0.8×1.2-cm hypoechoic solid nodule with a well-defined smooth margin and increased vascularity. The initial fine-needle aspiration (FNA) had a result of benign (Bethesda category 2). After 34 months, the patient presented with a palpable neck mass. C, D. Follow-up ultrasonography (C, longitudinal; D, color Doppler) reveals an increased nodule size $(1.7 \times 1.4 \times 4.1 \mathrm{~cm})$ with similar ultrasonographic features. The second FNA had a nondiagnostic result due to the paucity of retrieved cells. A subsequent core needle biopsy revealed metastatic renal cell carcinoma.

uniform characteristic US features, appearing as hypoechoic solid nodules $(100 \%)$ with well-defined smooth margins $(87.5 \%)$ and increased vascularity (100\%). All nodules were classified as high or intermediate suspicion according to the ATA guidelines and intermediate suspicion on K-TIRADS, which requires FNA of nodules $\geq 1 \mathrm{~cm}$.

FNA is widely accepted as a diagnostic tool for thyroid malignancies or metastases, with a reported sensitivity of $73.7 \%$ $94 \%$ and specificity up to $100 \%[8-10,19]$. However, the diagnostic yield of FNA specific to metastatic RCC needs further investigation, as false negative outcomes in FNA cytology have been increasingly recognized as a concern for these metastases. Chung et al. [2] searched PubMed for articles published between 2000 and 2010 on metastatic thyroid tumors and reported that preoperative FNA performed for thyroid metastases resulted in an incorrect diagnosis in 44 of 167 cases (26.3\%). Of these, RCC had the highest rate of inaccurate FNA results (28.6\%) [2]. In comparison, FNA showed high accuracy when used to diagnose other common metastatic malignancies, such as breast cancer (94.7\%) and lung cancer $(90.1 \%)$ [2]. Clinically significant inaccurate FNA rates specific to metastatic RCC have been further observed in other studies and case reports, with inaccuracy rates ranging up to $82.3 \%$ $[6,9,14,15,20-22]$. The majority of nondiagnostic FNA results were reported as benign or indeterminate $[6,14,20-22]$. On the other hand, CNB was able to accurately diagnose metastatic RCC without further investigation in most cases $[15,23]$.

In our study, only one nodule (11.1\%) was confirmed as metastatic carcinoma via FNA, whereas all performed CNBs were able to correctly diagnose metastatic RCC. This is consistent with previous findings in which CNB was found to reduce nondiagnostic results, with the diagnostic utility of CNB being superior to that of FNA $[15,24]$. A recent study including 46 metastatic thyroid nodules 
from various primary organs showed that all CNBs $(n=20)$ were able to confirm the diagnosis without inconclusive or incorrect results [15]. CNB has a higher sensitivity and a lower false negative rate than FNA, and was less likely to require a further diagnostic workup, especially for metastatic thyroid nodules [15].

The cause for this clinically significant rate of inaccurate or indeterminate FNA results in metastatic RCC compared to other metastatic tumors is not yet known. No study has demonstrated the limitations regarding the cytologic evaluation of metastatic RCC, and no study has addressed the possibility of renal clear cell cytology mimicking benign cytology. However, increased vascularity may be the most plausible reason for the low diagnostic yield of FNA. Hypervascular nodules are more likely to yield nondiagnostic results due to a higher likelihood of blood contamination, which makes cytologic examinations more difficult [25]. In addition, several intrinsic limitations associated with FNA may reduce its diagnostic efficacy in metastatic thyroid nodules. First, only cytologic examination is possible with cells retrieved from FNA [2]. Immunohistochemical staining with specific antibodies, which is often required to diagnose metastatic malignancies in the thyroid gland, cannot be performed with FNA specimens $[2,6,11]$. Immunohistochemical markers such as PAX2, RCC marker, CD10, vimentin, and alpha-methylacyl-CoA racemase are known to be useful in the diagnosis of metastatic RCC [26]. In the context of metastasis, FNA usually does not obtain adequate tissue samples for these staining techniques [26]. Second, cytologic evaluation alone cannot distinguish metastatic high-grade malignancy from primary anaplastic carcinoma [15]. Finally, FNA is not able to provide diagnostic information on rare primary-origin tumors, such as nonsquamous tumors or non-adenocarcinomas [15]. Histopathologic analysis shows a superior diagnostic performance compared to cytological analysis, and some authors recommend diagnostic surgery to manage thyroid nodules in patients with a history of underlying malignancy $[2,11]$.

This study has several limitations. First, our study included a small number of cases. Nine nodules may not reliably represent the US features of metastatic RCC. Furthermore, it is difficult to accurately evaluate the diagnostic yields of FNA and CNB based on a limited number of cases. Second, not all metastatic nodules were histopathologically confirmed with diagnostic surgery. Two of the nine nodules were finally diagnosed based on CNB results without diagnostic surgery.

In conclusion, metastatic RCC appears as oval-shaped hypoechoic solid nodules with well-defined smooth margins, no calcifications, and increased vascularity on ultrasonography. Characteristic US features along with a previous history of RCC should raise clinical suspicions, and CNB should be performed to make an accurate diagnosis.

ORCID: Ok Kyu Song: http://orcid.org/0000-0002-3914-9203; Ja Seung Koo: http://orcid.org/0000-0003-4546-4709; Jin Young Kwak: http://orcid.org/0000-00026212-1495; Hee Jung Moon: http://orcid.org/0000-0002-5643-5885; Jung Hyun Yoon: http://orcid.org/0000-0002-2100-3513; Eun-Kyung Kim: http://orcid.org/00000002-3368-5013

\section{Conflict of Interest}

No potential conflict of interest relevant to this article was reported.

\section{References}

1. Yoon JH, Kim EK, Kwak JY, Moon HJ, Kim GR. Sonographic features and ultrasonography-guided fine-needle aspiration of metastases to the thyroid gland. Ultrasonography 2014;33:40-48.

2. Chung AY, Tran TB, Brumund KT, Weisman RA, Bouvet M. Metastases to the thyroid: a review of the literature from the last decade. Thyroid 2012;22:258-268.

3. Surov A, Machens A, Holzhausen HJ, Spielmann RP, Dralle $H$. Radiological features of metastases to the thyroid. Acta Radiol 2016;57:444-450.

4. Shi JL, Zhou JQ, Li JP. Renal clear cell carcinoma with thyroid and parotid metastases: a case report. Oncol Lett 2015;10:2617-2619.

5. Prasad SR, Humphrey PA, Catena JR, Narra VR, Srigley JR, Cortez $A D$, et al. Common and uncommon histologic subtypes of renal cell carcinoma: imaging spectrum with pathologic correlation. Radiographics 2006;26:1795-1806.

6. Macedo-Alves D, Koch P, Soares V, Gouveia P, Honavar M, TaveiraGomes A. Thyroid metastasis from renal cell carcinoma: a case report after 9 years. Int I Surg Case Rep 2015;16:59-63.

7. De Stefano R, Carluccio R, Zanni E, Marchiori D, Cicchetti G, Bertaccini $A$, et al. Management of thyroid nodules as secondary involvement of renal cell carcinoma: case report and literature review. Anticancer Res 2009;29:473-476.

8. Kim TY, Kim WB, Gong G, Hong SJ, Shong YK. Metastasis to the thyroid diagnosed by fine-needle aspiration biopsy. Clin Endocrinol (Oxf) 2005;62:236-241.

9. Hegerova L, Griebeler ML, Reynolds JP, Henry MR, Gharib H. Metastasis to the thyroid gland: report of a large series from the Mayo Clinic. Am J Clin Oncol 2015;38:338-342.

10. Duggal NM, Horattas MC. Metastatic renal cell carcinoma to the thyroid gland. Endocr Pract 2008;14:1040-1046.

11. El Fakih RO, Delgado FA, Harstine LR. Marked thyroid enlargement secondary to renal cell carcinoma metastasis with acute respiratory failure. Thyroid 2009;19:917-918.

12. Lee MW, Batoroev YK, Odashiro AN, Nguyen GK. Solitary metastatic cancer to the thyroid: a report of five cases with fine-needle aspiration cytology. Cytojournal 2007;4:5. 
13. Diaconescu MR, Costea I, Glod M, Grigorovici M, Diaconescu S. Unusual malignant tumors of the thyroid gland. Chirurgia (Bucur) 2013;108:482-489.

14. Kobayashi K, Hirokawa M, Yabuta T, Fukushima M, Masuoka H, Higashiyama $T$, et al. Metastatic carcinoma to the thyroid gland from renal cell carcinoma: role of ultrasonography in preoperative diagnosis. Thyroid Res 2015;8:4.

15. Choi SH, Baek JH, Ha EJ, Choi YJ, Song DE, Kim JK, et al. Diagnosis of metastasis to the thyroid gland: comparison of core-needle biopsy and fine-needle aspiration. Otolaryngol Head Neck Surg 2016:154:618-625.

16. Lee YH, Baek JH, Jung SL, Kwak JY, Kim JH, Shin JH, et al. Ultrasoundguided fine needle aspiration of thyroid nodules: a consensus statement by the korean society of thyroid radiology. Korean J Radiol 2015;16:391-401.

17. Haugen BR, Alexander EK, Bible KC, Doherty GM, Mandel SJ, Nikiforov YE, et al. 2015 American Thyroid Association management guidelines for adult patients with thyroid nodules and differentiated thyroid cancer: the American Thyroid Association guidelines task force on thyroid nodules and differentiated thyroid cancer. Thyroid 2016;26:1-133.

18. Shin JH, Baek JH, Chung J, Ha EJ, Kim JH, Lee YH, et al. Ultrasonography diagnosis and imaging-based management of thyroid nodules: revised Korean Society of Thyroid Radiology consensus statement and recommendations. Korean J Radiol 2016;17:370-395.
19. Yang J, Schnadig V, Logrono R, Wasserman PG. Fine-needle aspiration of thyroid nodules: a study of 4703 patients with histologic and clinical correlations. Cancer 2007;111:306-315.

20. Di Stasi V, D'Antonio A, Caleo A, Valvano L. Metastatic renal cell carcinoma to the thyroid gland 24 years after the primary tumour. BMJ Case Rep 2013;2013:bcr2012007569.

21. Jallu $A$, Latoo $M$, Pampori R. Rare case of renal cell carcinoma with mandibular swelling as primary presentation. Case Rep Urol 2013;2013:806192.

22. Miah MS, White SJ, Oommen G, Birney E, Majumdar S. Late simultaneous metastasis of renal cell carcinoma to the submandibular and thyroid glands seven years after radical nephrectomy. Int J Otolaryngol 2010;2010:698014.

23. Riaz K, Tunio MA, Alasiri M, Elbagir Mohammad AA, Fareed MM. Renal cell carcinoma metastatic to thyroid gland, presenting like anaplastic carcinoma of thyroid. Case Rep Urol 2013;2013:651081.

24. Yeon JS, Baek JH, Lim HK, Ha EJ, Kim JK, Song DE, et al. Thyroid nodules with initially nondiagnostic cytologic results: the role of core-needle biopsy. Radiology 2013;268:274-280.

25. Moon WJ, Baek JH, Choi JW, Kim YJ, Ha EJ, Lim HK, et al. The value of gross visual assessment of specimen adequacy for liquid-based cytology during ultrasound-guided, fine-needle aspiration of thyroid nodules. Endocr Pract 2015;21:1219-1226.

26. Truong LD, Shen SS. Immunohistochemical diagnosis of renal neoplasms. Arch Pathol Lab Med 2011;135:92-109. 